\title{
Alphabetisches Verzeichnis der Mitarbeiter dieses Bandes
}

Prof. Dr. Gerd Althoff, Historisches Seminar der Universität Münster, Domplatz 20-22, 48143 Münster, S. 393

Morten AxвоE M. A., Bredevej 87, 2830 Virum, Dänemark, S. 1

Prof. Dr. Heinrich BECK, Breslauer Straße 14, 53340 Meckenheim, S. 1

Dr. Charlotte BEHR, 27 Killieser Avenue, London SW2 4NX, Großbritannien, S. 1

PD Dr. Alexandru Cizek, Seminar für Mittellateinische Philologie der Universität Münster, Salzstraße 53, 48143 Münster, S. 236

Dr. Philippe Depreux, Centre National de la Recherche Scientifique - Archéologie et territoires, Université de Tours, 3, Place Anatole-France, 37000 Tours, Frankreich, S. 94

Kai-Peter Ebel M. A., Zitzergasse 30, 61250 Usingen, S. 186

Prof. Dr. Karl Hauck, Habichtshöhe 21, 48151 Münster, S. 1

Hubert Hydman, Statens Historiska Museum, Box 5428, 11484 Stockholm, Schweden, S. 1

Prof. Dr. Hagen Keller, Historisches Seminar der Universität Münster, Domplatz 20-22, 48143 Münster, S. 112

Prof. Dr. Ludger KÖRNTGEN, Historisches Seminar - Abteilung für Mittelalterliche Geschichte - der Universität Tübingen, Wilhelmstraße 36, 72074 Tübingen, S. 159

Dr. Jan Peder Lamm, Enheten för utveckling och production, Statens Historiska Museum, Box 5428, 11484 Stockholm, Schweden, S. 1

Prof. Dr. Christel Merer, Seminar für Mittellateinische Philologie der Universität Münster, Salzstraße 53, 48143 Münster, S. 338 und 413

Dr. Alexandra PEsch, Westfälisches Museum für Archäologie - Amt für Bodendenkmalpflege, Fachreferat Mittelalter, Königsstraße 46, 48143 Münster, S. 1

Dr. Jan RüDIGER, Historisches Seminar der Universität Basel, Hirschgässlein 21, 4051 Basel, Schweiz, S. 213

Prof. Dr. Ludwig SIEP, Philosophisches Seminar der Universität Münster, Domplatz 23, 48143 Münster, S. 393

Prof. Dr. Nikolaus Staubach, Institut für Frühmittelalterforschung der Universität Münster, Salzstraße 41, 48143 Münster, S. 259 und 447

Dr. Egon WAMERs, Museum für Vor- und Frühgeschichte - Archäologisches Museum, Karmelitergasse 1, 60311 Frankfurt am Main, S. 132 
